\title{
EFFECTIVITY OF 2.1\% MINOCYCLINE OINTMENT AND 24\% ETHYLENEDIAMINETETRAACETIC ACID GEL AS A ROOT SURFACE CONDITIONING MATERIAL (A STUDY OF FIBRIN CLOT ADHESION WITH SCANNING ELECTRON MICROSCOPE)
}

\author{
ADITYO WIDARYONO, YUNIARTI SOEROSO*, SRI LELYATI \\ Department of Periodontics, Faculty of Dentistry, Universitas Indonesia, Jakarta, 10430, Indonesia. E-mail: yuniarti_22@yahoo.co.id \\ Received: 06 February 2019, Revised and Accepted: 13 February 2019
}

ABSTRACT

Objective: A stable fibrin clot adhesion on the root surface of the teeth is the start of periodontal regeneration. We aimed to observe the difference between fibrin clot adhesion on root surfaces after root surface conditioning using minocycline and ethylenediaminetetraacetic acid (EDTA).

Methods: We divided 30 root surfaces into three groups - namely, the minocycline group, the EDTA group, and the saline group as a control. We dropped fresh human blood on the root surface and allowed it to coagulate. We evaluated the fibrin clots using a scanning electron microscope.

Results: We found no significant differences between the minocycline and the EDTA applications ( $p=0.759)$.

Conclusions: EDTA and minocycline demonstrated equal capability in producing fibrin clots on the root surface.

Keywords: Periodontal regeneration, Root surface conditioning, Fibrin clot.

(c) 2019 The Authors. Published by Innovare Academic Sciences Pvt Ltd. This is an open access article under the CC BY license (http://creativecommons. org/licenses/by/4. 0/) DOI: http://dx.doi.org/10.22159/ijap.2019.v11s1.166

\section{INTRODUCTION}

Chronic periodontitis is inflammation of the periodontal tissue caused by bacterial plaque infection, accompanied by periodontal attachment loss and bone destruction, as well as tooth mobility [1-3]. On the basis of periodontal pocket depth, periodontitis is classified as mild, moderate, and severe if the pocket is $1-34-6$, and $>6 \mathrm{~mm}$, respectively [3]. Bacterial endotoxin is a component of lipopolysaccharide from the Gram-negative bacterial cell wall, which is demonstrably involved in the pathogenesis of periodontal disease, and is present in dental plaque, saliva, saliva exudate, and root surfaces with periodontal pockets [4].

A surgical treatment is indicated in cases of periodontitis with residual pockets of $6 \mathrm{~mm}$ or more [5]. By eliminating pathological structures containing cytotoxic material, root planing aims to provide a conductive root surface to regenerate periodontal attachment [6]. The formation of cementum, periodontal ligament, alveolar bone, and gingiva is the hallmark of periodontal regeneration [7]. Periodontal regeneration depends on the presence of stem cells in the periodontal ligament and the presence of molecular signals for mobilization and stimulation of these cells $[7,8]$. With periodontal disease, adsorption, adhesion, and maturation of fibrin clots between the gingival flap and the root surface are the beginning of the regeneration process [9].

A bacteria-contaminated cementum and a smear layer are almost always left by scaling and root planning [10]. This circumstance complicates the fibrin clot adhesion on the root surface and negatively affects periodontal regeneration $[9,11]$. The use of chemicals for the biomodification of the root surface (root surface conditioning) is one approach to increasing periodontal regeneration. The purposes of root conditioning are root surface detoxification, decontamination, and demineralization. This procedure eliminates the smear layer that occurs during mechanical instrumentation and exposes the dentine and cementum-collagen matrix [12]. The exposed dentine and cementumcollagen fibers will form more stable attachments to the fibrin present in the blood clot, prevent epithelial downgrowth, and form a temporary scaffold for cell growth and a mature collagen fiber adhesion $[7,13]$.
The application of $24 \%$ ethylenediaminetetraacetic acid (EDTA) with a $\mathrm{pH}$ of between 7 and 7.2 for 2-3 min achieves a more effective removal of the smear layer than that at lower concentrations $[14,15]$. Root surface conditioning with $24 \%$ EDTA at a neutral pH effectively eliminates the smear layer and opens the collagen matrix of dentine and cementum. Root surface conditioning with EDTA is also reported not to interfere with the vitality of the surrounding periodontium $[16,17]$ For these reasons, $24 \%$ EDTA at a neutral $\mathrm{pH}$ is considered the ideal agent for root surface conditioning $[16,18]$.

Minocycline hydrochloride $(\mathrm{HCl})$ is one of the most widely active strains of broad-spectrum tetracycline antibiotics against anaerobic Gramnegative bacteria [19]. Minocycline is also known for its inhibitory effect on collagenase $[20,21]$. On root surfaces, $2.1 \%$ minocycline $\mathrm{HCl}$ ointment can bind calcium and phosphate, opening the collagen matrix and eliminating the post-mechanical instrumentation smear layer [22]. These properties make the $2.1 \%$ minocycline $\mathrm{HCl}$ ointment potentially useful as a root surface conditioning agent $[7,20]$. In periodontal surgical treatment, Zhang et al. used the material as root surface conditioning and achieved enhanced clinical attachment compared with that achieved in treatment without root surface conditioning [20].

With root surface conditioning, clinicians expect to provide a conductive root surface for the stabilization of fibrin clots and the later attachment of connective tissue. Researchers have reported the efficacy of EDTA gel for root surface conditioning; now, minocycline $\mathrm{HCl}$ ointment presents an alternative. On this basis - with reference to the fibrin clot adhesion on the root surface - an analysis of the extent of the effects of EDTA gel and of minocycline ointment as a root surface conditioning material is necessary. The level of fibrin clotting will be observed through scanning electron microscope (SEM).

Our general objective in this study was to analyze, in vitro, the effectiveness of the root surface conditioning material in maximizing the fibrin clot adhesion on the tooth root surface. We specifically aimed to analyze the difference between the level of fibrin clot adhesion on the root surface achieved by root planing treatment only and that achieved 
with the application of $2.1 \%$ minocycline $\mathrm{HCl}$ ointment or buffered $24 \%$ EDTA gel as the root surface conditioner, after root planing.

\section{METHODS}

This study was a laboratory experimental study using the cervical third of the root proximal surface (the predilection area for periodontal disease). Teeth root surfaces were derived from extracted teeth because of periodontal disease and originating from nonsmoking patients. Fifteen teeth matching the criteria were obtained from the Periodontics Clinic of Teaching Hospital Faculty of Dentistry, Universitas Indonesia.

After extraction, the teeth were cleaned with distilled water and stored them in saline solution until the experiment was performed. With a highspeed cylindrical bur, two parallel fissures were made on both proximal surfaces (mesial and distal): one fissure was in the cementoenamel junction, and the other fissure was more apical by $4 \mathrm{~mm}$ than the first fissure. The root surface between the two fissures was smoothed with a 5/6 Gracey curette using 50 one-way apico-coronal pulls to remove contaminants and create a smear layer $[13,23]$.

The teeth were cut on the first and second fissures; then, they were cut into two parts on the axis of the tooth, thereby creating two blocks of root surface measuring $4 \mathrm{~mm} \times 2 \mathrm{~mm}$ (Fig. 1). The resulting 30 root surface blocks were stored in containers of PBS until the treatment was completed. Samples for each treatment group was taken randomly from 30 samples, with a total of 10 samples for each treatment group [13,23].

\section{Periocline minocycline group}

The smoothed root surface blocks were rubbed with a light pressure for $1 \mathrm{~min}$ at a time with a soft microbrush moistened with periocline (Fig. 2) three times (that is, for $3 \mathrm{~min}$ in total) and irrigated them each time using $10 \mathrm{~mL}$ PBS between the repetitions. The peripheral blood was immediately applied after treatment [20].

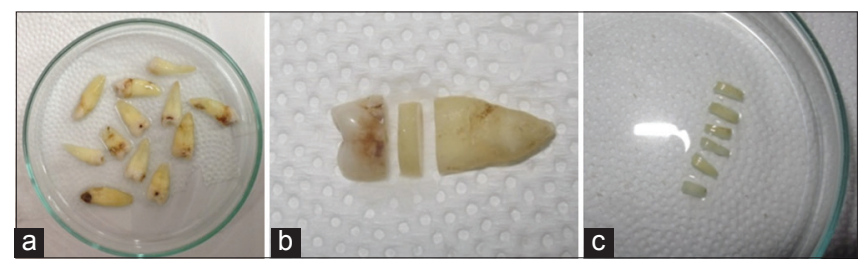

Fig. 1: (a-c) Cervical third of root proximal surface

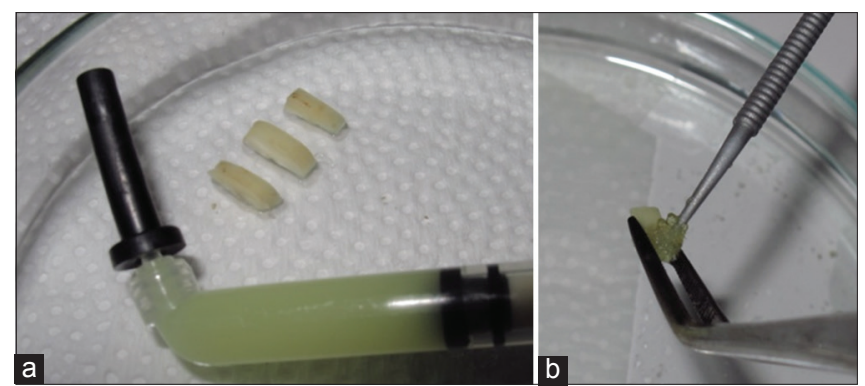

Fig. 2: (a and b) Periocline and its application to the sample

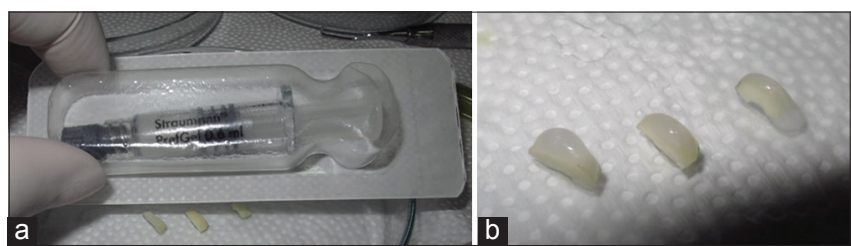

Fig. 3: (a and b) PrefGel ethylenediaminetetraacetic acid and its application to the sample
PrefGel ethylenediaminetetraacetic acid group

PrefGel was dripped onto the smoothed root surface blocks to cover the entire root surface blocks and left them for 2 min (Fig. 3); after which, we irrigated them using $10 \mathrm{~mL}$ PBS. The peripheral blood was immediately applied after treatment [23].

\section{Control group}

Normal irrigation was applied using $10 \mathrm{~mL}$ saline solution. The peripheral blood was immediately applied after treatment $[13,20,23]$.

\section{Fresh blood applications}

Competent officers took the peripheral blood. Immediately after the treatment, we dripped $0.1 \mathrm{~mL}$ of fresh peripheral blood from a healthy male donor onto each root surface block (Fig. 4). The blood was allowed to coagulate for $20 \mathrm{~min}$ and then rinsed the sample blocks three times, for 5 min each time, in a Petri dish containing PBS, in a circular motion using a low-speed tabletop shaker. The blood was applied once in a chamber with temperature of $37^{\circ} \mathrm{C}[9,13]$.

\section{Sample preparation for the scanning electron microscope}

Fixation was performed immediately after the application of peripheral blood to the sample. The dehydration, drying, and coating with conductive material of the samples were then evaluated with SEM.

\section{Steps [23-25]}

- Fixation with 2.5\% glutaraldehyde for $30 \mathrm{~min}$

- Blocks rinsed three times, for 5 min each, in a Petri dish containing PBS, in a circular motion, using a low-speed tabletop shaker

- Serial dehydration with ethanol $(30 \%, 50 \%, 70 \%, 90 \%, 95 \%$, and twice at $100 \%$ ) each for 5 min

- Final dehydration with hexamethyldisilazane (HMDS) twice, for 15 min each

- Sample placed in the fume chamber for $8 \mathrm{~h}$ at room temperature to allow for HMDS evaporation

- All steps performed at room temperature

- Sputtering/coating performed with conductive material using sputtering tool

- Samples stored in a desiccator at room temperature.

\section{Scanning electron microscope sample evaluation}

The sample was placed on the specimen plate and placed the plate on the inside of the SEM unit and then ran the SEM unit. The images were stored digitally, and they were then scored in a double-blind manner by three trained observers.

\section{Scoring system}

Determining the criteria of attachment level using SEM based on scoring $[13,23,26]$ (Fig. 5):

- Score 0: Absence of fibrin network and blood cells

- Score 1: Scarce fibrin network and/or blood cells

- Score 2: Moderate fibrin network and moderate quantity of blood cells

- Score 3: Dense fibrin network and trapped blood cells.

\section{Management and data analysis plan}

We included, in our study, results in a categorical measurement scale with more than two unpaired groups, and we therefore tested them with a non-parametric test (table $3 \times 3$ ). To determine the level of the fibrin clot adhesion on the root surface block, we used the Chi-square test with $\mathrm{p}<0.05$ regarded as statistically significant for our statistical analysis.

\section{RESULTS}

Three observers were selected and tested with the Cohen kappa test to determine agreement among observers. The kappa number was $0.861(>0.75)$ between the first and the second observers, indicating a satisfactory agreement between the first and the second observers; the kappa number was $0.813(>0.75)$ between the first and the third observers, indicating a satisfactory agreement between the first and 


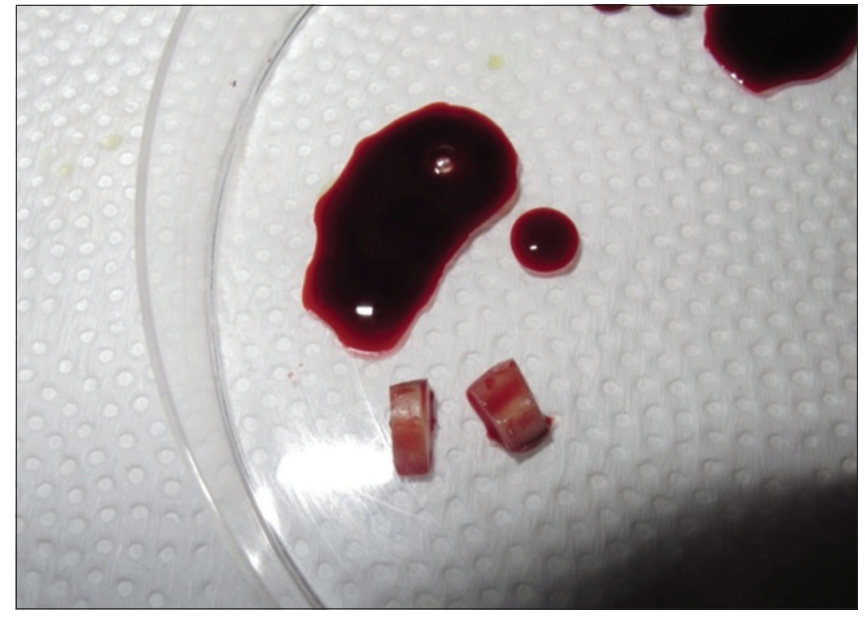

Fig. 4: Application of fresh human peripheral blood to obtain fibrin clots
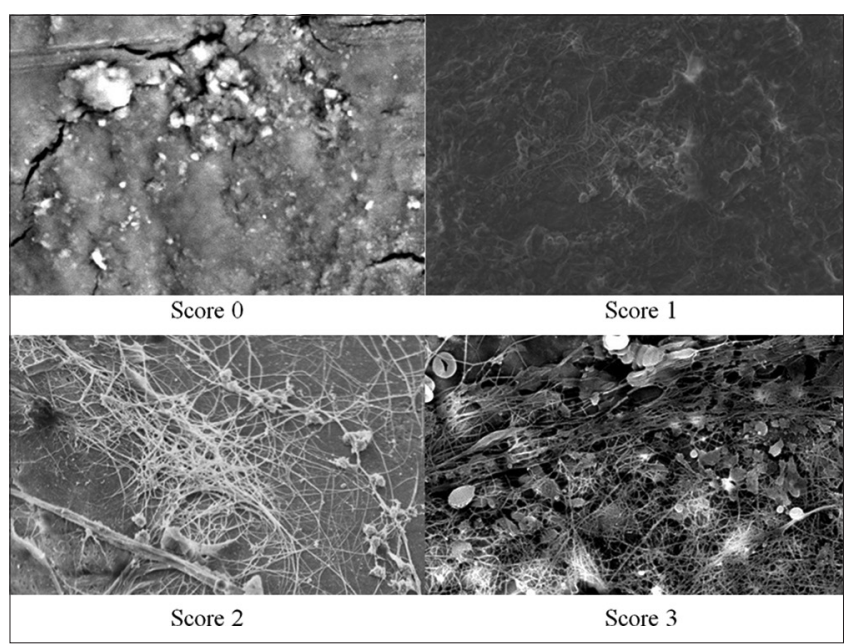

Fig. 5: Scanning electron microscope image example of each fibrin clot score

the third observers; the kappa number was $0.766(>0.75)$ between the second and the third observers. Each sample received the score that prevailed among the three observers. Table 1 shows the distribution of the fibrin clot density score from each treatment group.

In our experimental study, we used categorical variables with variability on a nominal scale (root surface conditioning) and ordinal scale (fibrin clot density) so that this study has a categorical scale variable problem. We had originally planned statistical data processing using the Chisquare test. This test, however, is not eligible for use because all cells had an expected count value of $<5$; we therefore replaced it with the Kolmogorov-Smirnov test to determine the significant differences among treatment groups.

As shown in Table 2, we found no significant difference $(p=0.400)$ between the minocycline root surface conditioning material and saline irrigation. Thus, we rejected the hypothesis that there was a difference between the fibrin clot adhesion on the root surface with root planing only and that with root surface conditioning using $2.1 \%$ minocycline $\mathrm{HCl}$ ointment after root planing

As shown in Table 2, we did, however, find a significant difference $(p=0.015)$ between EDTA root surface conditioning and saline irrigation. Thus, we accepted the hypothesis that there was a difference between the fibrin clot adhesion on the root surface with root planing only and with root surface conditioning using 24\% EDTA gel after root planing.

\section{DISCUSSION}

Changing the surface of the root that has been exposed to periodontal disease into a more appropriate environment for periodontal regeneration is an important first step in the regeneration process. Researchers have attempted to remove toxic deposits from tooth root surfaces in several ways. Scaling and root planing generates microcrystalline debris in a $2.15 \mathrm{\pi m}$ thick smear layer, firmly attached to the root surface; this can only be removed with root surface demineralization material [24]. Hence, demineralization of the root surface has been introduced with several materials to eliminate toxic material and the smear layer from the root surface. Thereafter, the root surface conditioning material is applied to open the cementum-collagen matrix and facilitate the adhesion between the root surface and - first - the blood component at the time of surgery and - second - connective tissue at the time of healing $[27,28]$.

The fibrin clot, in periodontal healing, forms an early adhesion to the root surface that later serves as a framework for periodontal stem cell migration and prevents deepening of the junctional epithelium. Therefore, in periodontal regeneration, the stabilization of fibrin clots plays a crucial role $[9,13,24]$.

We aimed in this study to compare root surface conditioning using EDTA and minocycline as materials, in terms of fibrin clot adhesion to the root surface. We used the saline control to illuminate any difference in fibrin clot adhesion to the root surface using the root surface conditioning method and without the method.

Fibrin clot adhesion on saline irrigation and root surface conditioning using $\mathbf{2 . 1 \%}$ minocycline hydrochloride ointment We found better fibrin clot adhesion for the minocycline treatment group than for the saline irrigation alone, but the difference was not statistically significant $(\mathrm{p}=0.400)$ between the two groups. This treatment group had the highest prevalence of the solid fibrin clot adhesion (score 3) (30\%). This suggested that there was good potential for facilitating fibrin clot adhesion in minocycline HCl. This potential may have been due to the ability of minocycline to eliminate the smear layer and to bind calcium phosphate, thereby opening the collagen matrix $[20,29]$. Zhang et al. had obtained a better clinical attachment using that material in periodontal surgical treatment than the attachment achieved without root surface conditioning [20]. The studies of Zhang et al. and Madison and Hokett (1997) also found that minocycline eliminates the smear layer more effectively than saline irrigation alone. Somerman et al.'s study also suggested that root surfaces treated with minocycline facilitate the adhesion of fibroblast cells [30].

Fibrin clot adhesion on saline irrigation and root surface conditioning using $24 \%$ ethylenediaminetetraacetic acid gel

We found in this study that EDTA resulted in a significantly better fibrin clot adhesion $(\mathrm{p}=0.015)$ compared with that of the saline control. This result was in accordance with a previous study by Leite et al., comparing saline and EDTA preparations in terms of fibrin clot adhesion [23]. They stated that EDTA - unlike saline - demonstrated a remarkable ability to eliminate the smear layer and to open a cementum-collagen matrix and also worked at a neutral $\mathrm{pH}$ [23].

We found that most saline controls $(70 \%)$ did not result in a fibrin clot adhesion (score 0). This was in accordance with the previous studies by Minocha and Rahul and Leite et al., where they suggested that most saline controls did not result in fibrin clot adhesion and at best resulted in a low fibrin clot density (score 1) [23,24]. According to Polson et al., a bacteria-contaminated cementum is almost always created and a smear layer is almost always left by the scaling and root planing procedure [10]. This circumstance, if not addressed, will complicate the attachment of fibrin clots to the root surface [11]. 
Table 1: Frequency distribution of fibrin clot density score between saline, minocycline, and ethylenediaminetetraacetic acid treatments*

\begin{tabular}{|c|c|c|c|c|c|}
\hline $\begin{array}{l}\text { Surface Treatment- Fibrin } \\
\text { Clot Density }\end{array}$ & Score 0 & Score 1 & Score 2 & Score 3 & Total \\
\hline \multicolumn{6}{|l|}{ Saline } \\
\hline $\mathrm{n}$ & 7 & 3 & 0 & 0 & 10 \\
\hline$\%$ total & 23.3 & 10.0 & 0.0 & 0.0 & 33.3 \\
\hline \multicolumn{6}{|l|}{ Minocycline } \\
\hline $\mathrm{n}$ & 4 & 2 & 1 & 3 & 10 \\
\hline$\%$ total & 13.3 & 6.7 & 3.3 & 10.0 & 33.3 \\
\hline $\mathrm{n}$ & 1 & 2 & 6 & 1 & 10 \\
\hline$\%$ total & 3.3 & 6.7 & 20.0 & 3.3 & 33.3 \\
\hline \multicolumn{6}{|l|}{ Total } \\
\hline $\mathrm{n}$ & 12 & 7 & 7 & 4 & 30 \\
\hline$\%$ total & 40.0 & 23.3 & 23.3 & 13.3 & 100.0 \\
\hline
\end{tabular}

Table 2: Analysis of differences between fibrin clot results for $\mathbf{2 . 1 \%}$ minocycline, $24 \%$ EDTA, and saline irrigation treatment

\begin{tabular}{ll}
\hline Analysis & p value \\
\hline saline irrigation versus minocycline & 0.400 \\
saline irrigation versus EDTA & $0.015^{*}$ \\
EDTA versus minocycline & 0.759 \\
\hline
\end{tabular}

* Kolmogorov-Smirnov test, $\mathrm{p}<0.05$ - significantly different.

EDTA: Ethylenediaminetetraacetic acid

Fibrin clot adhesion to the root surface after root surface conditioning using either $2.1 \%$ minocycline hydrochloride ointment or $24 \%$ ethylenediaminetetraacetic acid gel

We found no significant difference $(p=0.759)$ between the fibrin adhesion to the root surface after conditioning with $2.1 \%$ minocycline $\mathrm{HCl}$ and that with buffered $24 \%$ EDTA gel after root planing. In the EDTA group, we found the highest percentage $(60 \%)$ of moderate fibrin clot density (score 2). This was in accordance with Leite et al.'s study, which found that $24 \%$ EDTA had a high ability to eliminate smear layers and to open the cementum-collagen matrix and worked at a neutral $\mathrm{pH}$, but EDTA also had a strong calcium-binding character. Because one of the blood clotting factors is the calcium ion, this character could both inhibit the formation and adherence of blood clots to the root surface and accelerate the splitting off of the platelets that contribute to blood clotting [23]. Leite et al. found that the highest fibrin clot adhesion score (score 3) was not obtained, possibly because of the tendency of EDTA to be difficult to rinse [13], leaving residues attached to the root surface [24]. They argued that this EDTA residue may have disturbed the stability of the formed fibrin clot.

In the minocycline group, $40 \%$ of samples had a score of 0 (no fibrin clots on the root surface), and $30 \%$ of samples had score of 3 (solid fibrin clot adhesion). From this evidence, we deduced that minocycline $\mathrm{HCl}$ had an inconsistent ability to produce fibrin clot adhesion. This is in accordance with Shetty et al.'s study, which found the ability of minocycline to eliminate the smear layer to be less consistent than that of tetracycline [29]. The variation in fibrin clot adhesion obtained in our study may be due to the inconsistency of minocycline itself in smear layer elimination.

In their clinical study, Zhang et al. stated that the optimum viscosity of minocycline ointment simplified the control of the application area so that the damaging effects of the low $\mathrm{pH}$ of the material could be better controlled. When the minocycline was applied, injury to the periodontal ligament cells could be avoided by the use of cotton to protect the base area of the defect. Lee et al and Pitaru et al. also accepted the possibility that this result could be due to the periodontal stem cells more easily attaching to the treated root surfaces $[31,32]$. It can therefore be assumed that the regeneration process is highly dependent on the vitality of the periodontal ligament cells. An investigation into the toxic effects of root surface conditioning materials on periodontal ligament cells and how these materials affect the stem cell attachment to the root surface would be an important and necessary step in periodontal regeneration research.

\section{CONCLUSIONS}

Our study demonstrated that there was no difference between the fibrin clot adhesion on the root surface with root planing only and that with root surface conditioning using $2.1 \%$ minocycline $\mathrm{HCl}$ ointment after root planing. We also found no difference, after root planing, between the fibrin clot adhesion on the root surface with root surface conditioning using $2.1 \%$ minocycline $\mathrm{HCl}$ ointment and that using buffered 24\% EDTA gel. We found a significant difference only between the fibrin clot adhesion on the root surface with root planing only and that with root surface conditioning using 24\% EDTA gel after root planing.

\section{CONFLICT OF INTEREST}

There are no conflicts of interest to declare.

\section{REFERENCES}

1. Cobb CM. Non-surgical pocket therapy: Mechanical. Ann Periodontol 1996;1:443-90.

2. Drisko $\mathrm{CH}$. Nonsurgical periodontal therapy. Periodontol 2000 2001;25:77-88.

3. Novak M, Novak K. Chronic periodontitis. In: Newman M, Takei H, Klokkevold P, Carranza F, editors. Carranza's Clinical Periodontology. $10^{\text {th }}$ ed. St. Louis: Saunders; 2006. p. 494-9.

4. Pitaru S, Soldinger M, Madgar D, Metzger Z. Bacterial endotoxin inhibits migration, attachment, and orientation of human gingival fibroblasts in vitro and delays collagen gel contraction. J Dent Res 1987;66:1449-55.

5. Carranza F, Henry H, Cochran DL. Reconstructive periodontal surgery. In: Newman M, Henry H, Klokkevold P, Carranza F, editors. Carranza's Clinical Periodontology. Philadelphia, PA: WB Saunders Co.; 2006. p. $968-90$.

6. Armitage G. Biologic Basis of Scaling and Root Planing: Biologic Basis of Periodontal Maintenance Therapy. Berkeley: Praxis; 1980. p. $78-115$.

7. Polimeni G, Xiropaidis AV, Wikesjö UM. Biology and principles of periodontal wound healing/regeneration. Periodontol 2000 2006;41:30-47.

8. Grzesik WJ, Narayanan AS. Cementum and periodontal wound healing and regeneration. Crit Rev Oral Biol Med 2002;13:474-84.

9. Baker DL, Stanley Pavlow SA, Wikesjö UM. Fibrin clot adhesion to dentin conditioned with protein constructs: An in vitro proof-ofprinciple study. J Clin Periodontol 2005;32:561-6.

10. Polson AM, Frederick GT, Ladenheim S, Hanes PJ. The production of a root surface smear layer by instrumentation and its removal by citric acid. J Periodontol 1984;55:443-6.

11. Polson AM, Proye MP. Fibrin linkage: A precursor for new attachment. J Periodontol 1983;54:141-7.

12. Hanes PJ, Polson AM, Ladenheim S. Cell and fiber attachment 
to demineralized dentin from normal root surfaces. J Periodontol 1985;56:752-65.

13. Leite FR, Sampaio JE, Zandim DL, Dantas AA, Leite ER, Leite AA, et al. Influence of root-surface conditioning with acid and chelating agents on clot stabilization. Quintessence Int 2010;41:341-9.

14. Suchetha A, Darshan BM, Prasad R, Ashit GB. Root biomodification a boon or bane? Indian J Oral Sci 2011;2:251-5.

15. Pitaru S, Melcher AH. Organization of an oriented fiber system in vitro by human gingival fibroblasts attached to dental tissue: Relationship between cells and mineralized and demineralized tissue. J Periodontal Res 1987;22:6-13.

16. Heijl L, Sculean A. Application of enamel matrix proteins in intrabony defect: A biology based regenerative treatment. In: Sculean A, editor. Periodontal Regenerative Therapy. Berlin: Quintesscene; 2011. p. 90-102.

17. de Vasconcellos LM, Ricardo LH, Balducci I, de Vasconcellos LG, Carvalho YR. Histological analysis of effects of $24 \%$ EDTA gel for nonsurgical treatment of periodontal tissues. J Oral Sci 2006;48:207-14.

18. Wikesjo U, Polimeni G, Xiropaidis A, Stavropoulos A. Periodontal wound healing/regeneration. In: Sculean A, editor. Periodontal Regenerative Therapy. Berlin: Quintessence; 2011. p. 25-46.

19. Perno M. Pharmacotherapy in Periodontal Therapy. Access to Care Position Paper. Access ADHA; 2001. p. 1-12.

20. Zhang H, Shang S, Li C. The use of Minocycline-Hcl Ointment for Root Conditioning in Periodontal Surgery: A Preliminary Study. Hong Kong: Paper Presented At: The $9^{\text {th }}$ Asian Pacific Society of Periodontology Meeting; 2011

21. Greenwald RA, Golub LM, Lavietes B, Ramamurthy NS, Gruber B, Laskin RS, et al. Tetracyclines inhibit human synovial collagenase in vivo and in vitro. J Rheumatol 1987;14:28-32.

22. Atilla G, Baylas H. Effect of various demineralizing agents on mineral contents of cementum surfaces (an electron probe analysis). J Marmara Univ Dent Fac 1996;2:515-9.
23. Leite FR, Moreira CS, Theodoro LH, Sampaio JE. Blood cell attachment to root surfaces treated with EDTA gel. Braz Oral Res 2005;19:88-92.

24. Minocha T, Rahul A. Comparison of fibrin clot adhesion to dentine conditioned with citric acid, tetracycline, and ethylene diamine tetra acetic acid: An in vitro scanning electron microscopic study. J Indian Soc Periodontol 2012;16:333-41.

25. Oshel P. HMDS and specimen drying for SEM. Micros Today 1997;97:16.

26. Bansal P, Bansal P. Evaluation of fibrin clot adhesion as a precursor for new attachment following root conditioning. Pak Oral Dent $J$ 2010;30:176-83.

27. Blomlöf J, Lindskog S. Root surface texture and early cell and tissue colonization after different etching modalities. Eur J Oral Sci 1995; 103:17-24.

28. Theodoro LH, Sampaio JE, Haypek P, Bachmann L, Zezell DM, Garcia VG, et al. Effect of Er: YAG and diode lasers on the adhesion of blood components and on the morphology of irradiated root surfaces. J Periodontal Res 2006;41:381-90.

29. Shetty B, Dinesh A, Seshan H. Comparitive effects of tetracyclines and citric acid on dentin root surface of periodontally involved human teeth: A scanning electron microscope study. J Indian Soc Periodontol 2008; $12: 8-15$.

30. Somerman MJ, Foster RA, Vorsteg GM, Progebin K, Wynn RL. Effects of minocycline on fibroblast attachment and spreading. J Periodontal Res 1988;23:154-9.

31. Pitaru S, Gray A, Aubin JE, Melcher AH. The influence of the morphological and chemical nature of dental surfaces on the migration, attachment, and orientation of human gingival fibroblasts in vitro. J Periodontal Res 1984;19:408-18

32. Lee JY, Seol YJ, Park JR, Park YJ, Chung CP. Biological effects of a root conditioning agent for dentin surface modification in vitro. J Periodontal Implant Sci 2010;40:257-64. 